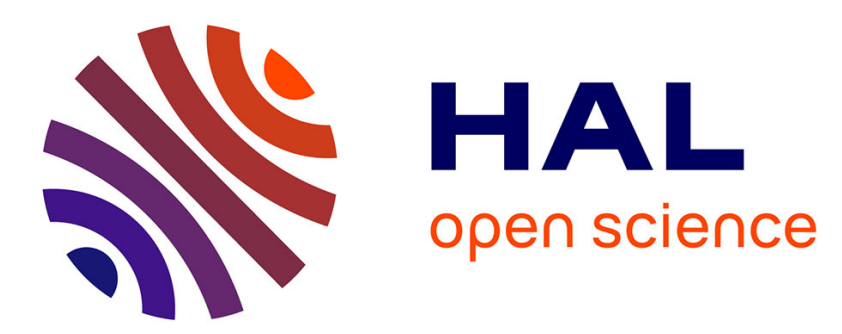

\title{
Increasing trend in gonococcal resistance to ciprofloxacin in the Netherlands, 2006-2008
}

Fdh Koedijk, M G Van Veen, a J De Neeling, G B Linde, M a B van Der Sande

\section{- To cite this version:}

Fdh Koedijk, M G Van Veen, a J De Neeling, G B Linde, M a B van Der Sande. Increasing trend in gonococcal resistance to ciprofloxacin in the Netherlands, 2006-2008. Sexually Transmitted Infections, 2010, 86 (1), pp.41. 10.1136/sti.2009.037135 . hal-00552820

\section{HAL Id: hal-00552820 \\ https://hal.science/hal-00552820}

Submitted on 6 Jan 2011

HAL is a multi-disciplinary open access archive for the deposit and dissemination of scientific research documents, whether they are published or not. The documents may come from teaching and research institutions in France or abroad, or from public or private research centers.
L'archive ouverte pluridisciplinaire HAL, est destinée au dépôt et à la diffusion de documents scientifiques de niveau recherche, publiés ou non, émanant des établissements d'enseignement et de recherche français ou étrangers, des laboratoires publics ou privés. 
Increasing trend in gonococcal resistance to ciprofloxacin in the Netherlands, 2006-2008

FDH Koedijk, MG van Veen, AJ de Neeling, GB Linde, MAB van der Sande, on

behalf of the Dutch STI centres and the Medical Microbiological Laboratories

\section{Corresponding author:}

FDH Koedijk

RIVM National Institute of Public Health and the Environment

P.O. Box 1

3720 BA Bilthoven

The Netherlands

Tel: +31302742864

Email: femke.koedijk@rivm.nl

FDH Koedijk, Centre for Infectious Disease Control, RIVM National Institute of Public Health and the Environment, P.O. Box 1, 3720 BA, Bilthoven, The Netherlands

Contribution: Implementation of the project, data analysis, writing of the manuscript

MG van Veen, Centre for Infectious Disease Control, RIVM National Institute of Public Health and the Environment, P.O. Box 1, 3720 BA, Bilthoven, The Netherlands

Contribution: Editing manuscript, input for discussion

AJ de Neeling, Centre for Infectious Disease Control, RIVM National Institute of Public Health and the Environment, P.O. Box 1, 3720 BA, Bilthoven, The Netherlands

Contribution: Editing manuscript, input for discussion, responsible for laboratory part of the surveillance

GB Linde, Municipal Health Service Amsterdam, Department of Infectious Diseases, Amsterdam, the Netherlands

Contribution: Editing manuscript, input for discussion, data delivery

MAB van der Sande, Centre for Infectious Disease Control, RIVM National Institute of Public Health and the Environment, P.O. Box 1, 3720 BA, Bilthoven, The Netherlands

Contribution: Editing manuscript, input for discussion, end responsibility

Dutch STI centres: A. van Daal (East), H. Fennema (North-Holland Flevoland), F. de Groot (North), C. Hoebe (Limburg), M. Langevoort (Utrecht), P. van Leeuwen (South-Holland North), J. van de Sande (Zeeland-Brabant), E. van der Veen (South-Holland South)

Medical Microbiological Laboratories: E. Stobberingh (Academisch Ziekenhuis Maastricht), A. van Griethuysen (Alysis Zorggroep Arnhem), G. Andriesse (Amphia Ziekenhuis Breda), E. de Brauwer (Atrium Medisch Centrum Heerlen), J. Mouton (Canisius-Wilhelmina Ziekenhuis Nijmegen), J. Marcelis (St. Elisabeth Ziekenhuis Tilburg), W. Goessens (Erasmus Medisch Centrum Rotterdam), P. Schneeberger (Jeroen Bosch Ziekenhuis 's Hertogenbosch), J. Schirm (Laboratorium voor Infectieziekten Groningen), A. Jansz (Laboratoria voor de Pathologische Anatomie en Medische Microbiologie Veldhoven), F. Stals (Laurentius Ziekenhuis Roermond), C. Janssen (Medisch Centrum Haaglanden Den Haag), J. Spaargaren (Streeklaboratorium Enschede), A. Speksneijder (Streeklaboratorium Amsterdam), J. van Zeijl (Streeklaboratorium Leeuwarden), L. Sabbe (Streeklaboratorium Zeeland), E. Mattsson (Universitair Medisch Centrum Utrecht), T. Trienekens (VieCuri Medisch Centrum Venlo)

Key words: Gonorrhoea, Gonococci, Surveillance, Antibiotic resistance, STD clinic 
The Corresponding Author has the right to grant on behalf of all authors and does grant on behalf of all authors, an exclusive licence (or non exclusive for government employees) on a worldwide basis to the BMJ Publishing Group Ltd to permit this article (if accepted) to be published in STI and any other BMJPGL products and sub-licences such use and exploit all subsidiary rights, as set out in our licence http://sti.bmjjournals.com/ifora/licence.pdf).

\section{Contribution of each author:}

FDH Koedijk: Implementation of the project, data analysis, writing of the manuscript

MG van Veen: Editing manuscript, input for discussion

AJ de Neeling: Editing manuscript, input for discussion, responsible for laboratory part of the surveillance

GB Linde: Editing manuscript, input for discussion, data delivery

MAB van der Sande: Editing manuscript, input for discussion, end responsibility

\section{Key messages:}

- Ciprofloxacin resistance is still increasing in the Netherlands

- No resistance to current first choice therapy has been found yet, however, monitoring is essential

- By merging epidemiology with microbiology in GRAS, risk groups for antimicrobial resistance can be identified and treatment guidelines can be adjusted timely when needed. 


\section{Abstract}

\section{Introduction}

Rapid development of Neisseria gonorrhoeae resistance to several antibiotics in recent years threatens treatment and prevention. Targeted surveillance of new resistance patterns and insight into networks and determinants are essential to control this trend.

\section{Methods}

Since the Gonococcal Resistance to Antimicrobials Surveillance project (GRAS) was implemented within the Dutch national STI surveillance network in July 2006, participating STI centres have collected a culture from each gonorrhoea patient. Isolates were tested for susceptibility to penicillin, tetracycline, ciprofloxacin, and cefotaxime using Etest ${ }^{\circledR}$. Logistic regression was used to determine risk factors for ciprofloxacin resistance.

\section{Results}

Between July 2006 and July 2008, prevalence of resistance to penicillin was 10\%, to tetracycline $22 \%$, and to ciprofloxacin $42 \%$. Resistance to cefotaxime was not found, although minimum inhibitory concentrations (MIC) higher than $0.125 \mathrm{mg} / \mathrm{L}$ drifted upward $(p<0.05)$. Ciprofloxacin resistance rose from $35 \%$ in 2006 to $46 \%$ in 2008 $(p<0.05)$, despite 2003 guidelines naming cefotaxime as first choice therapy. In men, ciprofloxacin resistance was higher in men having sex with men (MSM) than in heterosexual men (adjusted OR: 2.0, 95\%Cl: 1.5-2.6). In women, it was higher in commercial sex workers (adjusted OR: 25.0, 95\% $\mathrm{Cl}: 7.7-78.2$ ) and women aged over 35 years (adjusted OR: 8.2, 95\% Cl: 3.0-22.7) than in other women.

\section{Conclusion}

Ciprofloxacin resistance in the Netherlands is increasing, and is particularly found in MSM, older women, and female sexworkers. No resistance to current first choice therapy was found, but alertness to potential clinical failures is essential. By merging epidemiological and microbiological data in GRAS, specific high-risk transmission groups can be identified and policy adjusted when needed. 


\section{Introduction}

Gonorrhoea is the second most common bacterial sexually transmitted infection (STI) in the Netherlands. Under the national sentinel surveillance program in STI centres, 1,827 cases were reported in $2007 .{ }^{1}$ Approximately $69 \%$ of the male cases were diagnosed among men who have sex with men (MSM), with a positivity rate of $8.9 \%$. In heterosexual men and women, the positivity rate was $1.5 \%$ and $1.1 \%$ respectively. In $2007,14 \%$ of the new cases of gonorrhoea diagnosed were in people who had a known to have an HIV infection, and $2 \%$ were simultaneously diagnosed with an HIV infection and gonorrhoea. ${ }^{1}$ An infection with gonorrhoea increases the risk of acquiring HIV infection and may increase the viral load in those already HIVinfected. $^{2}$ Infection with $N$. gonorrhoeae in men and women is an important cause of epididymitis, cervicitis, urethritis, and pelvic inflammatory disease (PID). PID may further lead to ectopic pregnancy, infertility or abortion.

Rapid and appropriate treatment of gonorrhoea is of great importance for public health, because it shortens the infectious period and limits transmission of the disease. The World Health Organisation (WHO) recommends that first-choice therapy for gonorrhoea needs to cure at least $95 \%$ of those infected. ${ }^{3}$ National surveillance of antimicrobial resistance in gonococci was conducted in the Netherlands from 1976 until 1999, the period in which reporting the disease was mandatory. Since then, national insight into its incidence, and also into resistance patterns of gonococci, has been lacking, despite signs of increases in gonorrhoea infections and in resistance to fluoroquinolones such as ciprofloxacin., ${ }^{4,5}$ Initially, penicillin was the primary therapy for gonorrhoea in the Netherlands. In 1997, the spread of penicillin-resistant $N$. gonorrhoeae led to modification of the guidelines towards single-dose therapy with ciprofloxacin or ceftriaxone. Indications of increasing quinolone resistance resulted in another revision of the guidelines in 2003, making cefotaxime the first choice therapy for gonorrhoea infections. At the end of 2006, ceftriaxone was selected as primary therapy. ${ }^{6}$ Results from an annual nationwide laboratory questionnaire, administered since 2002 , showed a remarkable increase in resistance to quinolones from $6.6 \%$ in 2002 to $26.4 \%$ in $2005 .^{7}$ The questionnaire did not collect any epidemiological or clinical information on the gonorrhoea patients. As this is essential to ensure adequate and updated treatment and prevention guidelines, the project "Gonococcal Resistance to Antimicrobials Surveillance" (GRAS) was initiated in 2006. Here, we analyse and discuss methods and results of the first two years of GRAS, with a focus on the determinants of resistance to ciprofloxacin (prior first-choice therapy) and $3^{\text {rd }}$ generation cephalosporins (current first-choice of therapy). 


\section{Methods}

GRAS is implemented within the present Dutch national STI surveillance network, in which 32 STI centres and laboratories across eight regions provide free STI testing and care to people in specific high-risk groups, included those who wish to be tested anonymously. ${ }^{1}$ This system of testing and care was set up in addition to the routine national health services, to reach people who might otherwise not seek timely STI care. The population under study in GRAS were all patients in participating STI centres who were diagnosed with a gonorrhoea infection between July 2006 and July 2008.

\section{Susceptibility testing}

From July 2006 until July 2008, all participating STI centres collected a sample for culture and susceptibility testing from each gonorrhoea patient. In July 2006, GRAS was implemented in its first participating STI centre. Throughout the years 2006 to 2008, the project was further implemented, and as of June 2008, it included 13 of the Dutch STI centres, representing $83 \%$ of the total population of clinic attendees. Three STI centres stopped participating in 2007 for logistical or financial reasons.

The antimicrobial susceptibility of gonococcal isolates was tested locally at the laboratories related to the STI centres; each isolate was tested for its susceptibility to penicillin, tetracycline, ciprofloxacin, and cefotaxime (since this was first choice therapy when implementing GRAS in June 2008) using Etest $\AA^{\circledR}$ (AB Biodisk, Solna, Sweden). Minimum inhibitory concentrations (MIC) breakpoints were $\geq 2 \mathrm{mg} / \mathrm{L}$ for penicillin, $\geq 1 \mathrm{mg} / \mathrm{L}$ for ciprofloxacin, $\geq 2 \mathrm{mg} / \mathrm{L}$ for tetracycline and $>0.5 \mathrm{mg} / \mathrm{L}$ for cefotaxime, according to guidelines recommended by the CLSI. ${ }^{8}$

To enable comparability of the microbiological data, a quality control system was developed for GRAS, based on the standards for quality control in surveillance of antibiotic resistance that were devised by the Dutch Foundation of the Working Party on Antibiotic Policy. ${ }^{9}$ At the beginning of participation in GRAS, the laboratories tested a panel of four control strains (including N. gonorrhoeae ATCC49226 and three strains kindly provided by $\mathrm{C}$. Ison). Each laboratory was allowed to use its own methods, including the agar medium, but had to identify the MIC of each antibiotic for the four reference strains. The MIC of the ATCC reference strain had to be within the boundaries prescribed by the CLSI.

\section{Data collection and analysis}


For routine national surveillance, new STI consultations and corresponding diagnoses were reported to the Dutch Centre for Infectious Disease Control, facilitated by a web-based application (SOAP). An anonymous report is submitted for each visitor, containing epidemiological, clinical data, and test results on a wide range of STIs. For GRAS, MIC values were collected for each patient diagnosed with gonorrhoea and reported in SOAP. The Chi-square test was used to assess significance of differences among groups. Time trends in antimicrobial resistance were assessed by using the Chi-square test for trends. Associations between ciprofloxacin-resistant and ciprofloxacin-susceptible patients were analysed using logistic regression models. Multivariate analysis was performed by using all variables with clinical and statistical importance $(p<0.05)$, stratified by gender. All statistical analyses were performed using SPSS software, version 15.0.

\section{Results}

Between July 2006 and July 2008, susceptibility testing for N. gonorrhoeae was performed for isolates from 1,556 patients (174 in 2006; 939 in 2007, and 443 in the first half of 2008), covering $66 \%$ of all patients $(n=2,377)$ diagnosed in the participating STI centres (since they started or till they stopped participating). No laboratories were excluded since comparable results were achieved for the quality control; mean ${ }^{2} \log$ (MIC) of the four reference strains of any laboratory did not differ more than 1.5 from the overall mean ${ }^{2} \log (\mathrm{MIC})$ of each antibiotic.

Most of the patients with an isolate were men (87\%), of whom $73 \%$ were from MSM (table 1 ); $61 \%$ of the cases were people of Dutch origin, and $21 \%$ were HIV positive (prior to or simultaneous with their gonorrhoea diagnosis). Patients with an isolate differed significantly from patients without an isolate, according to most of the main characteristics (table 1). Patients with an isolate were more often male, older, from the Western part of the Netherlands, non-Dutch, MSM, and HIV-positive. No significant trends in time in patient characteristics were found, except for HIV status and region.

Results show a prevalence of resistance to ciprofloxacin of $42 \%$ (increasing significantly from $35 \%$ in 2006 to $46 \%$ in $2008, p<0.05$ ), to tetracycline of $22 \%$ (changing over time from $22 \%$ in 2006 to $27 \%$ in 2008, p<0.05) and to penicillin of $10 \%$ (decreasing over time from $10 \%$ in 2006 to $7 \%$ in $2008, p=0.06$ ). Resistance to cefotaxime was not found. 
Of all tested isolates, 39\% $(n=600)$ were resistant to one of the antimicrobial tested, $14 \%(n=220)$ for two, and $3 \%(n=39)$ for three of the antimicrobials tested; $45 \%$ $(n=697)$ were susceptible to all tested antimicrobials.

Table 1. Characteristics of gonorrhoea patients with and without an isolate for susceptibility testing, the Netherlands, July 2006- July 2008

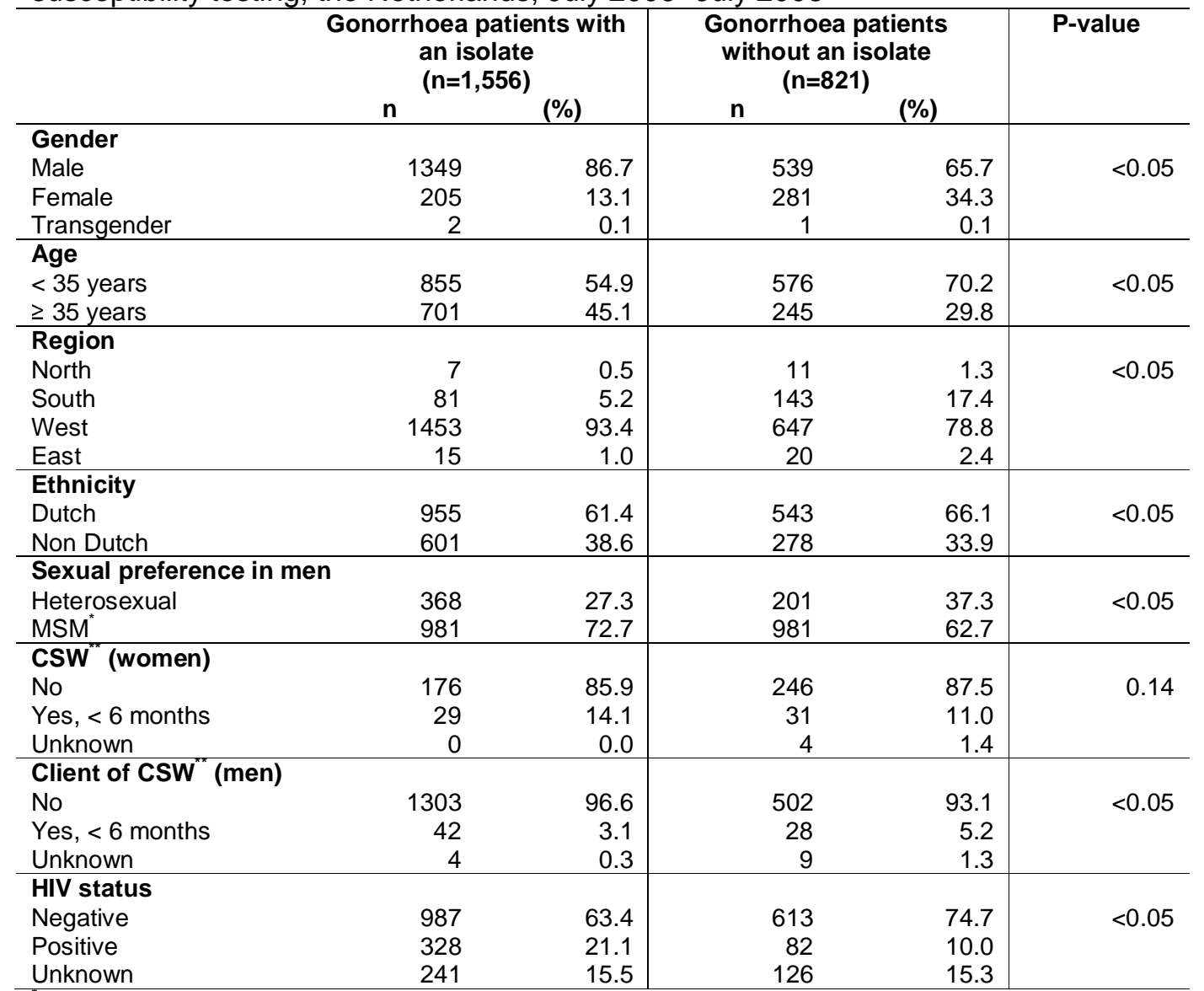

MSM: men having sex with men

"CSW: Commercial sex worker

\section{Ciprofloxacin resistance}

N. gonorrhoeae infection with ciprofloxacin-resistant bacteria increased from $35 \%$ in 2006 to $46 \%$ in 2008 ( $p<0.05$, figure 1). Univariate analyses showed that the risk of an infection with ciprofloxacin resistant gonorrhoea increased significantly over time in men (table 1) It was also found that isolates from men aged over 35 years were more likely to be resistant to ciprofloxacin than those from younger men (OR 1.6, table 2). Furthermore, ciprofloxacin resistance was significantly higher in MSM than in heterosexual men (OR: 2.3). Infection with $N$. gonorrhoeae resistant to ciprofloxacin was more likely in Dutch than non-Dutch men (OR 1.6), and in HIVpositive men than in HIV-negative men (OR 1.5). Being a client of a commercial sex worker (CSW), urbanisation and region were no significant risk factors. Five variables 
were significant in the univariate regression analyses and were included in the final multivariate logistic regression model for men (table 2). When adjusted for all these factors, only MSM and year of consultation were found to be associated with ciprofloxacin resistance in men (adjusted OR 2.0 for MSM and 1.5 and 1.6 for 2007 and 2008 respectively). As with men, ciprofloxacin resistance was higher in women older than 35 years (OR 6.0, table 2). Furthermore, women who reported commercial sex contacts in the past six months were more likely to be resistant to ciprofloxacin than women who did not (OR 25.2). Dutch women were less likely than non-Dutch women to be infected with a $N$. gonorrhoeae resistant to ciprofloxacin (OR 0.6, but not significantly). When these three variables were tested in a multivariate model, age above 35 years and CSW remained significant risk factors for resistance to ciprofloxacin in women (adjusted OR 8.2 and 25.0, respectively).

Table 2. Univariate and multivariate analyses on ciprofloxacin resistance for men and women separately, the Netherlands, July 2006-July 2008

\begin{tabular}{|c|c|c|c|c|c|c|}
\hline & \multicolumn{3}{|c|}{ Men } & \multicolumn{3}{|c|}{ Women } \\
\hline & $\begin{array}{c}\text { Nr. of } \\
\text { resistant } \\
\text { isolates } \\
(\%)\end{array}$ & $\begin{array}{c}\text { Univariate } \\
\text { analysis OR } \\
(95 \% \mathrm{Cl})\end{array}$ & $\begin{array}{c}\text { Multivariate } \\
\text { analysis OR } \\
(95 \% \mathrm{Cl})\end{array}$ & $\begin{array}{c}\text { Nr. of } \\
\text { resistant } \\
\text { isolates } \\
(\%)\end{array}$ & $\begin{array}{c}\text { Univariate } \\
\text { analysis OR } \\
(95 \% \mathrm{Cl})\end{array}$ & $\begin{array}{c}\text { Multivariate } \\
\text { analysis OR } \\
(95 \% \mathrm{Cl})\end{array}$ \\
\hline \multicolumn{7}{|c|}{ Year of consultation } \\
\hline 2006 & $56(35.9)$ & ref & & $52(28.6)$ & ref & \\
\hline 2007 & 359 (44.5) & $1.4(1.0-2.0)$ & $1.5(1.0-2.1)$ & $0(0.0)$ & $1.4(0.4-4.4)$ & - \\
\hline 2008 & $182(47.2)$ & $1.6(1.1-2.3)$ & $1.6(1.1-2.4)$ & $8(36.4)$ & $1.8(0.5-6.4)$ & - \\
\hline \multicolumn{7}{|l|}{ Age } \\
\hline$<35$ & $262(38.8)$ & ref & ref & $43(24.0)$ & & \\
\hline$\geq 35$ & $335(49.8)$ & $1.6(1.3-1.9)$ & $1.3(1.0-1.6)$ & $17(65.4)$ & $6.0(2.5-14.4)$ & $8.2(3.0-22.7)$ \\
\hline \multicolumn{7}{|l|}{ Ethnicity } \\
\hline Non- Dutch & $181(37.0)$ & ref & & $37(33.6)$ & ref & ref \\
\hline Dutch & $416(48.4)$ & $1.6(1.3-2.0)$ & $1.2(1.0-1.6)$ & $23(24.2)$ & $0.6(0.3-1.2)^{*}$ & $0.6(0.3-1.4)$ \\
\hline \multicolumn{7}{|c|}{ Sexual preference (men) } \\
\hline Heterosexual & $111(30.2)$ & & & - & & \\
\hline MSM & $486(49.5)$ & $2.3(1.8-2.9)$ & $2.0(1.5-2.6)$ & - & - & - \\
\hline \multicolumn{7}{|l|}{ CSW (women) } \\
\hline No & - & & & $35(58,3)$ & & \\
\hline $\begin{array}{l}\text { Yes, last } 6 \\
\text { months }\end{array}$ & - & - & - & $25(51,7)$ & $25.2(8.2-77.1)$ & $25.0(7.7-78.2)$ \\
\hline \multicolumn{7}{|l|}{ HIV status } \\
\hline Negative & $334(41.5)$ & ref & & $52(28.6)$ & ref & \\
\hline Positive & $167(51.2)$ & $1.5(1.1-1.9)$ & $1.1(0.8-1.4)$ & $0(0.0)$ & & . \\
\hline Unknown & $96(53.8)$ & $1.1(0.8-1.5)$ & $1.1(0.7-1.5)$ & $8(36.4)$ & $1.4(0.6-3.6)$ & - \\
\hline
\end{tabular}

\section{Cephalosporin resistance}

No resistance to cefotaxime was found. The distribution of MIC values for cefotaxime showed a slight upward drift between 2006 and 2008 (figure 2), as the proportion of isolates with an MIC value higher than $0.125 \mathrm{mg} / \mathrm{L}$ increased significantly in that period $(p<0.05)$. An MIC value of $0.38 \mathrm{mg} / \mathrm{L}$ was found in seven isolates, of which five were from MSM. 


\section{Discussion}

The prevalence of $N$. gonorrhoeae resistant to ciprofloxacin has increased to $46 \%$ in 2008, despite 2003 revision of the guidelines mandating its replacement by third generation cephalosporins. While resistance to cefotaxime was not found, an upward shift among its MIC values was observed during the study period. These findings suggest that in the future, novel (multi drug) treatment options might be needed to treat $N$. gonorrhoeae effectively, to prevent an upsurge of gonorrhoea infections. Antimicrobial resistance in $N$. gonorrhoeae is a growing worldwide public health problem. ${ }^{10}$ Increasing trends in ciprofloxacin resistance have been observed in most European countries, as well as in other countries worldwide. ${ }^{10-12}$

In the Netherlands, prevalence of ciprofloxacin resistance increased significantly over time in men and was found to be significantly higher in MSM than in heterosexual men, whereas in women, CSW and women aged above 35 years were most likely to have an infection with ciprofloxacin-resistant bacteria.

Current findings show that risk-group patterns of resistance to the newer antibiotics echo patterns seen when penicillin resistance emerged in the Netherlands in the '80s. Penicillin resistance was mainly associated with transmission in high-risk individuals like CSW and MSM, ${ }^{13-15}$ and these high-risk groups are now most likely to acquire an infection caused by ciprofloxacin-resistant bacteria, according to reports published worldwide. ${ }^{12,16,17}$ Insight into resistance patterns in diverse sexual networks may add to our understanding of the transmission dynamics of gonorrhoea in these populations. The presence of distinct heterosexual and homosexual networks, each showing sustained transmission, ${ }^{18-20}$, may explain the ongoing increase in the prevalence of ciprofloxacin resistance despite its decreased use in the STI centres in the Netherlands. The guidelines of the national society for venereology and dermatology were changed in 2003 and recommended that ciprofloxacin be replaced by third generation cephalosporins, as in many other countries. ${ }^{6,21,22}$ However, outside the STI centres in the Netherlands ciprofloxacin may still be prescribed for $N$. gonorrhoeae, especially since general practitioner (GP) guidelines still mentioned ciprofloxacin as the second choice of therapy in $2008^{23}$ (guidelines will be updated in 2009).

All isolates we tested were susceptible to cefotaxime, and no failures in its treatment of gonorrhoea had yet been reported in the Netherlands. However, we observed an upward shift in its MIC values, reported by GRAS participants. Isolates showing reduced susceptibility (MIC value $0.38 \mathrm{mg} / \mathrm{L}$ ) to cefotaxime and ceftriaxone have been reported since before 2006 in Asia and Australia ${ }^{24,25}$ and also recently in Europe ${ }^{26}$, 
although therapeutic failures have not been reported. Therefore, monitoring the susceptibility to cephalosporins is of high importance.

These first results from the GRAS project should nevertheless be interpreted with caution. The characteristics of patients from whom bacteria were isolated or not, differed significantly for some variables, and susceptibility testing was performed in only $66 \%$ of all gonorrhoea patients diagnosed at the participating STI centres in the study period. Moreover, an important obstacle to obtain samples for susceptibility testing is the need to store and transport them rapidly and appropriately to a laboratory for culturing. All STI centres participating in GRAS were instructed to grow cultures for susceptibility testing, but specimen collection and transport failed on some occasions. Also, some of the samples having a positive PCR test and negative culture results representing a false positive PCR. Finally, some STI centres asked for a culture only when an (asymptomatic) patient reported back for treatment due to a positive PCR, and some of these patients may have spontaneously recovered from the infection or obtained treatment elsewhere. At the moment, research is ongoing to evaluate the possibility of using molecular techniques (PCR) to monitor resistance patterns, in order to circumvent the cumbersome transport and storage procedures needed to enable culturing.

Another limitation of GRAS is its focus on high risk patients attending STI centres, rather than members of the general public visiting their GP. In the Netherlands, there is currently no systematic collection of data on the susceptibility patterns of gonorrhoea patients diagnosed by GPs )or by other health care professionals outside the STI centre system), although approximately $70 \%$ of all STIs in the Netherlands are diagnosed by GPs. ${ }^{27}$ Unlike Chlamydia however, transmission of $N$. gonorrhoeae appears to occur predominantly among high-risk groups. ${ }^{1}$ Therefore targeted surveillance of $N$. gonorrhoeae resistance among high-risk transmitters, as monitored by GRAS, is important for early detection of changing resistance patterns as this may necessitate modification of treatment guidelines. Targeted surveillance also enables, to explore risk factors for infection with such strains, and to understand high-risk transmission patterns. Development of resistance in the wider community is associated with the importation of new strains and their spread in the community following initial transmission in high-risk groups. ${ }^{28,29}$ Indeed, these high-risk groups are the groups visiting the STI centres.

In conclusion, by merging epidemiological data with data on antimicrobial resistance in GRAS, we identified specific risk groups, enabling adjusted treatment guidelines for these groups. Our results show that the prevalence of ciprofloxacin resistance in the Netherlands is still increasing and is particularly high in MSM, older women and 
female CSW. Resistance to the current first choice of therapy has not been found yet. However, monitoring and clinical awareness is essential, since the MIC values of cefotaxime are increasing. 


\section{Acknowledgements}

The authors thank all STI centres and medical microbiology laboratories in the Netherlands for their contribution in data collection: A. van Daal (East), H. Fennema (North-Holland Flevoland), F. de Groot (North), C. Hoebe (Limburg), M. Langevoort (Utrecht), P. van Leeuwen (South-Holland North), J. van de Sande (ZeelandBrabant), E. van der Veen (South-Holland South), E. Stobberingh (Academisch Ziekenhuis Maastricht), A. van Griethuysen (Alysis Zorggroep Arnhem), G. Andriesse (Amphia Ziekenhuis Breda), E. de Brauwer (Atrium Medisch Centrum Heerlen), J. Mouton (Canisius-Wilhelmina Ziekenhuis Nijmegen), J. Marcelis (St. Elisabeth Ziekenhuis Tilburg), W. Goessens (Erasmus Medisch Centrum Rotterdam), P. Schneeberger (Jeroen Bosch Ziekenhuis 's Hertogenbosch), J. Schirm (Laboratorium voor Infectieziekten Groningen), A. Jansz (Laboratoria voor de Pathologische Anatomie en Medische Microbiologie Veldhoven), F. Stals (Laurentius Ziekenhuis Roermond), C. Janssen (Medisch Centrum Haaglanden Den Haag), J. Spaargaren (Streeklaboratorium Enschede), A. Speksneijder (Streeklaboratorium Amsterdam), J. van Zeijl (Streeklaboratorium Leeuwarden), L. Sabbe (Streeklaboratorium Zeeland), E. Mattsson (Universitair Medisch Centrum Utrecht), T. Trienekens (VieCuri Medisch Centrum Venlo). Furthermore, the authors would like tot thank the steering group GRAS (J. van Bergen, W. Goessens, C. Janssen, H. van Kruchten, I. Linde, M. van Ogtrop, P. Oostvogel, E. Stobberingh, V. Sigurdsson, J. Spaargaren and P. van Voorst Vader), the Dutch Working Party on Antibiotic Policy (SWAB), as well as M. van de Laar and K. Borgen for their participation in the project, and M. van SantenVerheuvel for skilful technical assistance. 


\section{References}

1. van den Broek IVF, Koedijk FDH, van Veen MG, Op de Coul ELM, van Sighem Al, van der Sande MAB. Sexually Transmitted Infections in the Netherlands in 2007. Bilthoven: Centre for Infectious Disease Control - National Institute for Public Health and the Environment (RIVM); 2008. Report No.: 210261004/2008.

2. Kaul R, Pettengell C, Sheth PM, et al. The genital tract immune milieu: an important determinant of HIV susceptibility and secondary transmission. J Reprod Immunol 2008;77(1):32-40.

3. World Health Organization. Syndromic Management. Guidelines for the management of sexually transmitted infections. Geneva, Switserland; 2003:3-32. 4. de Neeling AJ, van Santen-Verheuvel M, Spaargaren J, Willems RJ. Antimicrobial resistance of Neisseria gonorrhoeae and emerging ciprofloxacin resistance in the Netherlands, 1991 to 1998. Antimicrob Agents Chemother 2000;44(11):3184-5.

5. Kolader M, Peerbooms PG, Vader PC, van Bergen JE, Fennema JS, de Vries HJ. [The rise in fluoroquinolone-resistant Neisseria gonorrhoeae among people attending the Municipal Health Service's clinic for sexually transmitted diseases in Amsterdam, the Netherlands; cefotaxime now first-choice treatment for uncomplicated gonorrhoea]. Ned Tijdschr Geneeskd 2004;148(43):2129-32.

6. SOA-commissie/SOA-kernwerkgroep NVDV. Soa-richtlijnen Nederlandse Vereniging voor Dermatologie en Venereologie (NVDV), augustus 2006.

7. Koedijk FDH, Borgen K, van Loo IH, van de Laar MJW. Further increase of quinolone resistance of gonococci in the Netherlands and proposal for a new surveillance. Ned Tijdschr Geneeskd 2007;151(2):142-3.

8. Clinical and Laboratory Standards Institute. Approved standard M100-S17. Performance Standards for Antimicrobial Susceptibility Testing; Seventeenth Informational Supplement 2007;27(1).

9. Resistentie Surveillance Standaard van de Stichting Werkgroep Antibiotica Beleid SWAB. 1999. (Accessed at http://www.swab.nl/.)

10. Tapsall J. Antibiotic resistance in Neisseria gonorrhoeae is diminishing available treatment options for gonorrhea: some possible remedies. Expert Rev Anti Infect Ther 2006;4(4):619-28.

11. Centers for Disease Control and Prevention (CDC). Sexually Transmitted Disease Surveillance, 2003. Supplement, Gonococcal Isolate Surveillance Project (GISP) Annual Report 2005. Atlanta: CDC; 2006. 
12. Fenton KA, Ison C, Johnson AP, et al. Ciprofloxacin resistance in Neisseria gonorrhoeae in England and Wales in 2002. Lancet 2003;361(9372):1867-9.

13. Prins M, Bindels PJ, Coutinho RA, Henquet CJ, van Doornum GJ, van den Hoek JA. Determinants of penicillinase producing Neisseria gonorrhoeae infections in heterosexuals in Amsterdam. Genitourin Med 1994;70(4):247-52.

14. van Duynhoven YT, van Klingeren B, van Santen-Verheuvel MG, van der Meijden WI, van de Laar MJ. Molecular epidemiology of infections with Neisseria gonorrhoeae among visitors to a sexually transmitted diseases clinic. Sex Transm Dis 1997;24(7):409-17.

15. Garcia S, Casco R, Perazzi B, De Mier C, Vay C, Famiglietti A. [Ciprofloxacin resistance of Neisseria gonorrhoeae according to sexual habits.]. Medicina (Buenos Aires) 2008;68(5):358-62.

16. Centers for Disease Control and Prevention (CDC). Increases in fluoroquinolone-resistant Neisseria gonorrhoeae among men who have sex with men--United States, 2003, and revised recommendations for gonorrhea treatment, 2004. MMWR Morb Mortal Wkly Rep 2004;53(16):335-8.

17. Le Lin B, Pastore R, Liassine N, Aramburu C, Sudre P. A new sexually transmitted infection (STI) in Geneva? Ciprofloxacin-resistant Neisseria gonorrhoeae, 2002-2005. Swiss Med Wkly 2008;138(15-16):243-6.

18. Kolader ME, Dukers NH, van der Bij AK, et al. Molecular epidemiology of Neisseria gonorrhoeae in Amsterdam, The Netherlands, shows distinct heterosexual and homosexual networks. J Clin Microbiol 2006;44(8):2689-97.

19. Martin IM, Ison CA, Aanensen DM, Fenton KA, Spratt BG. Changing epidemiologic profile of quinolone-resistant Neisseria gonorrhoeae in London. $J$ Infect Dis 2005;192(7):1191-5.

20. Morris SR, Knapp JS, Moore DF, et al. Using strain typing to characterise a fluoroquinolone-resistant Neisseria gonorrhoeae transmission network in southern California. Sex Transm Infect 2008;84(4):290-1.

21. Centers for Disease Control and Prevention (CDC). Update to CDC's sexually transmitted diseases treatment guidelines, 2006: fluoroquinolones no longer recommended for treatment of gonococcal infections. MMWR Morb Mortal Wkly Rep 2007;56(14):332-6.

22. Roy K, Wang SA, Meltzer MI. Optimizing treatment of antimicrobial-resistant Neisseria gonorrhoeae. Emerg Infect Dis 2005;11(8):1265-73.

23. Nederlands Huisartsen Genootschap. NHG-standaard Het Soa-consult. In: Nederlands Huisartsen Genootschap; 2004. 
24. Tanaka M, Nakayama $\mathrm{H}$, Huruya $\mathrm{K}$, et al. Analysis of mutations within multiple genes associated with resistance in a clinical isolate of Neisseria gonorrhoeae with reduced ceftriaxone susceptibility that shows a multidrug-resistant phenotype. Int J Antimicrob Agents 2006;27(1):20-6.

25. Whiley DM, Limnios EA, Ray S, Sloots TP, Tapsall JW. Diversity of penA alterations and subtypes in Neisseria gonorrhoeae strains from Sydney, Australia, that are less susceptible to ceftriaxone. Antimicrob Agents Chemother 2007;51(9):3111-6.

26. Tzelepi E, Daniilidou M, Miriagou V, Siatravani E, Pavlidou E, Flemetakis A. Cluster of multidrug-resistant Neisseria gonorrhoeae with reduced susceptibility to the newer cephalosporins in Northern Greece. J Antimicrob Chemother 2008;62(3):637-9.

27. van Bergen JE, Kerssens JJ, Schellevis FG, Sandfort TG, Coenen TJ, Bindels PJ. Prevalence of STI related consultations in general practice: results from the second Dutch National Survey of General Practice. Br J Gen Pract 2006;56(523):104-9.

28. Handsfield HH, Rice RJ, Roberts MC, Holmes KK. Localized outbreak of penicillinase-producing Neisseria gonorrhoeae. Paradigm for introduction and spread of gonorrhea in a community. JAMA 1989;261(16):2357-61.

29. Hook EW, 3rd, Brady WE, Reichart CA, Upchurch DM, Sherman LA, Wasserheit JN. Determinants of emergence of antibiotic-resistant Neisseria gonorrhoeae. J Infect Dis 1989;159(5):900-7. 
Figure 1: Ciprofloxacin resistance to N. gonorrhoeae, GRAS July 2006-July 2008

Figure 2: MIC distribution of cefotaxime, GRAS July 2006- July 2008

Word count: 2417 


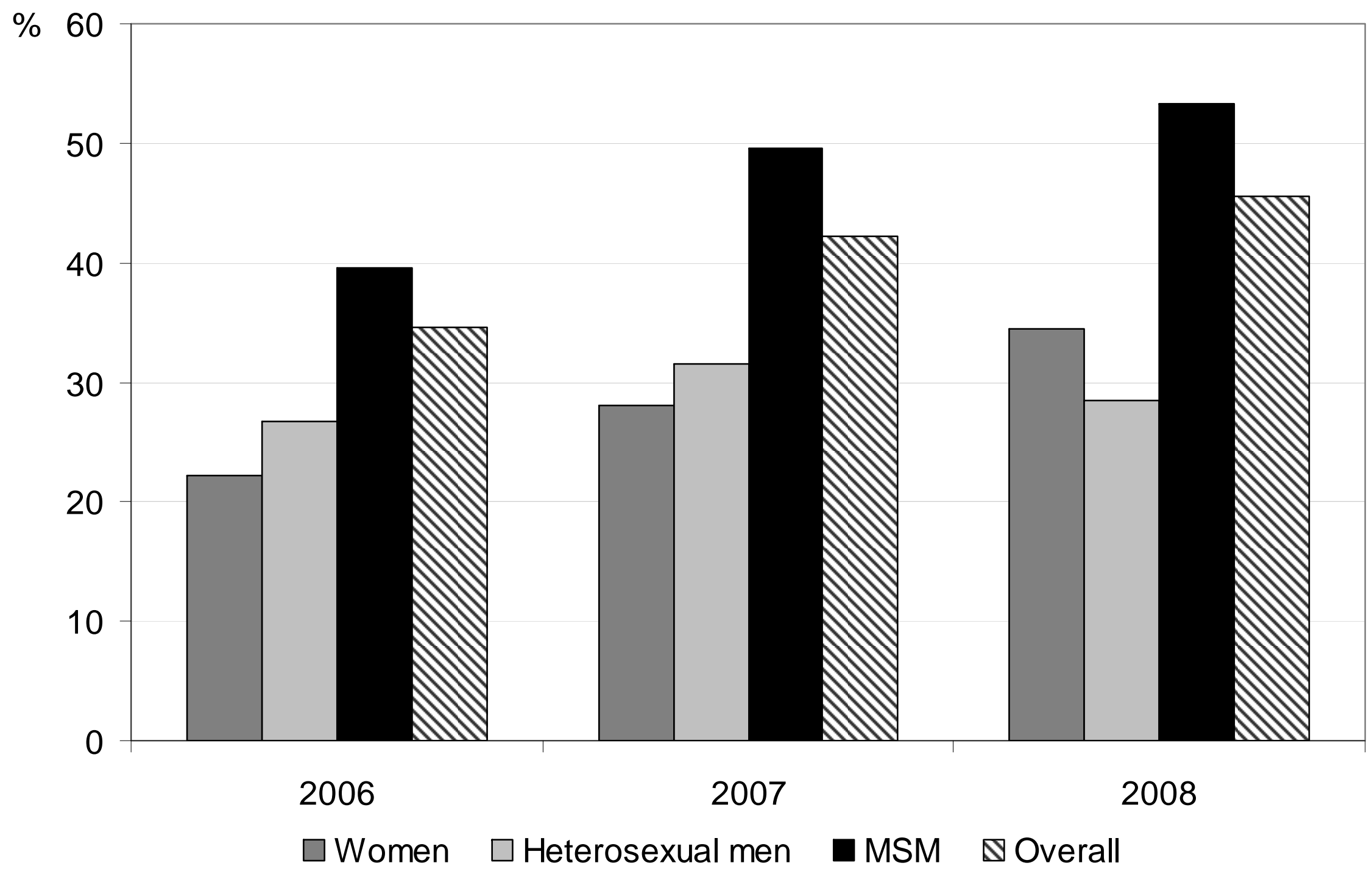




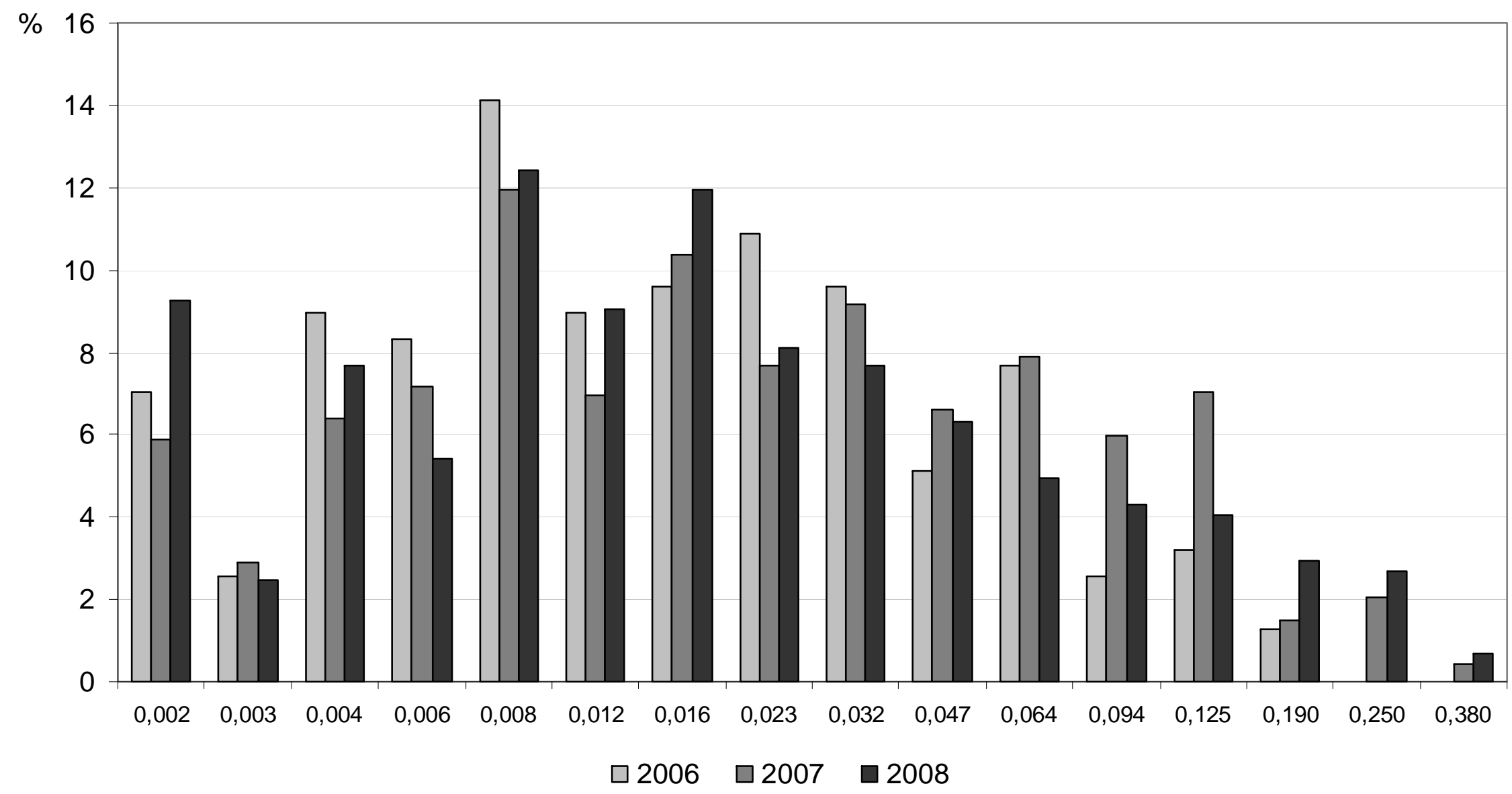

